\title{
Randomized Controlled Trial Between Vaginal Misoprostol Alone Versus Weighted Intrauterine Foley's Catheter and Vaginal Original Misoprostol in Termination of Mid-Trimester Abortion
} Article

\author{
Ebtsam Desouky, Alaa El Feky, Amr A. Al Aziz Elsayed
}

Department of Obstetrics and Gynecology, Faculty of Medicine, Ain-Shams University, Cairo

\begin{abstract}
Background: Termination of pregnancy (TOP) is defined as elective expulsion or extraction of products of conception from the uterus instead of spontaneous onset of the process irrespective of duration of pregnancy.

Aim: This work aimed to investigate whether the insertion of a weighted fluid filled trans-cervical Foley's catheter in women undergoing midtrimester termination of pregnancy for various reasons; may further improve the effectiveness of vaginal misoprostol in terminating their pregnancies.

Materials and Methods: A prospective, interventional, randomized controlled trial was conducted on a total number of 50 patients divided into two groups; the first group (I) included 25 patients who received vaginal misoprostol, two tablets each contains 200 microgram misoprostol (Segma pharmaceuticals, Egypt) in the posterior vaginal fornix every four hours. The mean induction delivery interval was $23.17 \pm 6.19$ in group I, $18.47 \pm 7.34$ in group II ( $25 \%$ reduction). Results: The use of a weighted trans-cervical Foley's catheter filled with $30 \mathrm{ml}$ saline improve the effectiveness of $400 \mu \mathrm{g}$ vaginal misoprostol in terminating mid trimester pregnancies as reflected by a shorter induction to delivery interval with no significant increase in the incidence of side effects.

Conclusion: The use of a weighted trans-cervical Foley's catheter filled with $30 \mathrm{ml}$ saline improve the effectiveness of $400 \mu \mathrm{g}$ vaginal misoprostol in terminating mid trimester pregnancies as reflected by a shorter induction to delivery interval with no significant increase in the incidence of side effects.
\end{abstract}

Key Words: Foley's catheter, termination of mid trimester abortion, vaginal misoprostol

Received: 28 September 2019, Accepted: 28 September 2019

Corresponding Author: Ebtsam Desouky, Department of Obstetrics and Gynecology, Faculty of Medicine, Ain-Shams University, Cairo Tel.: 01069491030,E-mail: desoukyebtsam@gmail.com

ISSN: 2090-7265, May 2021, Vol.11, No. 2

\section{INTRODUCTION}

Abortion is defined as termination of pregnancy (TOP) by any means before the fetus is viable. Viability is now considered to be reached at 23-24 weeks of gestation, Second trimester, or midtrimester, is a period ranging from 13 to 28 weeks of gestation, which again is subdivided into early midtrimester abortion between 13 and 20 weeks and a late midtrimester abortion between 20 and 28 weeks $^{[1]}$.

Mid trimester uterine evacuation is a process in which the contents of the uterus are removed during the second trimester of pregnancy. It can be performed electively, for fetal or pregnancy complications, or for maternal medical indications ${ }^{[2]}$.

Worldwide, mid-trimester abortion constitutes $10-15 \%$ of all induced abortions but is responsible for two-thirds of all major complications ${ }^{[3]}$.
Although the majority of abortions are performed in the first trimester,the ability to identify foetal abnormalities at an early stage by using ultrasonography and modern prenatal diagnostic techniques has increased the number of women requiring $\mathrm{TOP}^{[4]}$.

Indications for second trimester termination of pregnancy are variable, they are usually performed for Anticipated benefits to the mother, such as improving a medical condition which is caused or aggravated by pregnancy, including pre-eclampsia, placental abruption and certain respiratory, hepatic and cardiac disorders; or any other medical disorder affect the mother health. However, congenital fetal malformations; which are incompatible with lifealso constitute amajor indicator for $\mathrm{TOP}^{[5]}$.

Several regimens for second trimester medical abortion have been published. Most of these are based on Misoprostol, which is a synthetic prostaglandin E1 analogue (PGE1) and is either used alone, or combined with 
Mifepristone, other regimens used mechanical methods as intracervical catheters for termination of pregnancy in second trimester ${ }^{[6]}$

Several studies have described that the Foley's catheter is an effective method in ripening the cervix These studies showed that it increased the Bishop's score in women with unripe cervices and Foley's catheter appears to be superior to prostaglandins for pre-induction cervical ripening ${ }^{[7]}$.

\section{AIM OF THE WORK}

This study was designed to investigate whether the insertion of a weighted fluid filled trans-cervical Foley's catheter in women undergoing midtrimester termination of pregnancy for various reasons; may further improve the effectiveness of vaginal misoprostol in terminating their pregnancies.

\section{PATIENTS AND METHODS}

This prospective, interventional, randomized controlled trial (RCT) was conducted on 50 women with an indication for second trimester termination at the Obstetrics and Gynecology Department. The methods were explained to them and only those who consented were randomised for the study. Women who meet the selection criteria were informed about the procedures.

The study included patients with gestational age between 14-24 weeks with pregnancies sonographically diagnosed with a fetal anomaly incompatible with life and fetal demise.

Cases with contra-indication to misoprostol, e.g. bronchial asthma and coronary heart disease and renal failure and low lying placenta were excluded from the study.

These criteria were assessed during the initial evaluation as the following: 1. Complete history taking. 2. Clinical examination with special emphasis on; pulse, blood pressure and temperature. Cervical dilatation and consistency by vaginal digital examination Presence or absence of vaginal bleeding. 3. Laboratory investigations: Complete blood picture. Prothrombin time, bleeding time, clotting time and INR. Liver enzymes. Kidney function. Random blood sugar. 4. Pelvic ultrasound to detect: Number of gestations, viability and gestational age.

Failure of Induction was considered when the time of induction exceeded 48 hours. All patients received 20 mIU intravenous oxytocin after expulsion of the fetus. If the placenta did not separate in 30 minutes, the patient was anaesthetized and underwent surgical evacuation.

All women were be observed for the occurrence of side effects during the procedure and for the first 12 hours after termination. Results were then tabulated and statistically analyzed.
Method of randomization : A randomization sheet developed by Microsoft Excel which contains 50 patients randomly assigned into 2 groups (group I and group II) each group of 25 patients. The randomization was concealed using the sequentially numbered opaque sealed envelope (SNOSE). 50 opaque easy opening envelopes had been numbered serially, in each envelope the corresponding letter in randomization sheet was placed in one box. Pregnant women were allocated to each group according to the letter inside the envelope.

Methods of Intervention: Group (I) Vaginal misoprostol by inserting two tablets; each contains 200 microgram misoprostol (Segma pharmaceuticals, Egypt), in the posterior vaginal fornix every four hours.

Group (II) vaginal misoprostol with intra uterine catheter; termination was induced by inserting a $16 \mathrm{~F}$ Foley's catheter the patient in the lithotomy position, the cervix was visualized using a Cusco's speculum and then was cleaned with povidone Iodine. The anterior lip of the cervix was grasped with a ring forceps and another ring forceps was used to push the catheter through the cervix under direct visualization. The balloon was inflated with $(30 \mathrm{ml}-50 \mathrm{ml})$ saline and the catheter was pulled back against the internal os.

A bag filled with $(1000 \mathrm{ml})$ saline was applied to the distal end of the catheter to provide moderate traction. A 400 ug misoprostol vaginal dose "two tablets" was inserted in the posterior vaginal fornix/4 hours as in group (I). Re-assessment of the dilatation and effacement of the cervix was carried.

Participants were assessed every 4 hours for vital signs, cervical dilatation, expulsion of fetus and occurrence of complications.

\section{STATISTICAL ANALYSIS:}

Recorded data was analyzed using the statistical package for social sciences, version 20.0 (SPSS Inc., Chicago, Illinois, USA). Quantitative data were expressed as mean \pm standard deviation (SD). Qualitative data was expressed as frequency and percentage.

The following tests were done: Independentsamples t-test of significance was used when comparing between two means. Chi-square $\left(\mathrm{X}^{2}\right)$ test of significance was used in order to compare proportions between qualitative parameters. The confidence interval was set to $95 \%$ and the margin of error accepted was set to $5 \%$. So, the p-value was considered significant as the following: Normally distributed numerical data were presented as mean and SD, and skewed data as median and interquartile range. Qualitative data were presented as number and percentage. Comparison of normally distributed numerical data was done using unpaired $t$ test. Skewed data were compared using the 
Mann-Whitney test. Categorical data were compared using the chi-squared test. A two-sided $p$-value $<0.05$ will be considered statistically significant. Probability (P-value); $P$-value $<0.05$ was considered significant. $P$-value $<0.001$ was considered as highly significant. $P$-value $>0.05$ was considered insignificant.

\section{RESULTS}

There is a statistical difference between the study groups as regarding no. of doses $(P<0.05)$. The mean no. of doses was $5.84 \pm 2.01$ in group I, $4.09 \pm 2.09$ in group II, adecrease of about $30 \%$ (Table 1).

There is statistical difference between the study groups as regarding induction expultion interval "hrs" $(P<0.05)$. The mean induction delivery interval was $23.17 \pm 6.19$ in group I, $18.47 \pm 7.34$ in group II, with a decrease of about $25 \%$ (Table 2).

Table 3 shows no statistically significant difference between groups according to mode of abortion.

Table 1: Comparison between groups according to No. of doses

\begin{tabular}{lccc}
\hline No. of doses & Group I $(\mathrm{n}=25)$ & Group II $(\mathrm{n}=23)$ & t-test \\
\hline Mean \pm SD & $5.84 \pm 2.01$ & $4.09 \pm 2.09$ & 3.297 \\
Range & $3-8$ & $2-7$ & $0.019 *$ \\
\hline
\end{tabular}

Table 2: Comparison between groups according to induction expultion interval (hrs)

\begin{tabular}{|c|c|c|c|c|}
\hline $\begin{array}{l}\text { Induction delivery } \\
\text { interval (hrs) }\end{array}$ & $\begin{array}{c}\text { Group I }(\mathrm{n}=25) 23.17 \pm 6.19 \\
15-30\end{array}$ & $\begin{array}{c}\text { Group II }(\mathrm{n}=23) 18.47 \pm 7.34 \\
11-26\end{array}$ & t-test & $p$-value \\
\hline Mean \pm SD & $23.17 \pm 6.19$ & $18.47 \pm 7.34$ & \multirow[b]{2}{*}{2.405} & \multirow[b]{2}{*}{$0.023^{*}$} \\
\hline Range & $15-30$ & $11-26$ & & \\
\hline
\end{tabular}

Table 3: Comparison between groups according to mode of abortion

\begin{tabular}{|c|c|c|c|c|}
\hline Mode of abortion & Group I ( $\mathrm{n}=25)$ & Group II ( $n=23$ ) & $x^{2}$ & $p$-value \\
\hline Dilatation \&curettage & $3(12.0 \%)$ & $0(0.0 \%)$ & & \\
\hline Suction \&evacuation & $6(24.0 \%)$ & $9(39.1 \%)$ & 3.656 & 0.161 \\
\hline $\begin{array}{l}\text { Complete spontaneous } \\
\text { evacuation }\end{array}$ & $16(64.0 \%)$ & $14(60.9 \%)$ & & \\
\hline
\end{tabular}




\section{DISCUSSION}

The study was designed to investigate whether the insertion of a weighted fluid filled trans-cervical Foley's catheter would further improve the effectiveness of 400 $\mu \mathrm{g}$ vaginal misoprostol in terminating mid trimester pregnancies.

This study showed that the combination of Foley's catheter and misoprostol resulted in a significantly shorter induction to abortion interval compared to misoprostol alone. Because we used similar misoprostol dose in both groups, this decrease in duration was attributed to the use of weighted Foley's catheter with moderate traction applied over its distal end.

Both groups in the study had similar average age, parity, gravidity, gestational age.There were no differences in the indications for induction of Abortion in both groups. IUFD was the most common indication, followed by CFMF.

There was statistically significant difference between the study groups as regarding induction delivery interval. The time needed to complete abortion in group (II) was shorter than the time needed in group (I).

As regards the number of doses needed in each group, there was statistical significant differences was detected. There were no differences in complications in both groups.

In the present study, there was no significant difference in the need for post abortive manual separation of the placenta. Surgical evacuation should only be considered if there is clinical evidence that the abortion is incomplete. In the current study an incidence of $24 \%$ was reported in the misoprostol group while $39 \%$ required surgical evacuation in the combined group.an incidence of $12 \%$ was reported in the misoprostol group need D\&C but in combined group no case reported.

It is probably wise to inform women undergoing pregnancy termination early in the second trimester of possible higher chance of incomplete abortion.

During the implementation of the study, it became clear that the selection criteria pre-determined before starting the study have limited the population of the study to a group that is highly selective and with a higher than normal probability for reaching a successful outcome of induction of abortion; thus, leading to a low incidence of failed inductions.
Generalizing the results of the current study must be approached with caution as the context within which the study was performed can not be widely applied.

Details of the comparison between the current study and previous studies in the literature are discussed further in the following paragraphs.

Early studies comparing the Foley's catheter with PGE2 tablets found no difference in the termination time between both method. No traction was applied in either of these studies. Bani-Irshaid et al. ${ }^{[8]}$ compared the efficacy and safety of Foley's catheter (with and without traction) and prostaglandin E2 vaginal tablets in terminating second and early third trimester pregnancies in 258 women. They concluded that the efficacy of the Foley's catheter can be enhanced with the use of traction to give similar results to prostaglandin E2. The catheter exerts its effect by disrupting the integrity of amnion-chorion and myometrium in addition to cervical collagen increasing prostaglandin and cytokines release rendering the uterus susceptible ${ }^{[9]}$

Ashok et al. ${ }^{[10]}$ studied midtrimester medical termination of pregnancy using misoprostol and concluded that surgical evacuation of the uterus under general anesthesia was required to complete the abortion in $8.1 \%$ of women. In 2005 the Scottish group estimated the rate of surgical evacuation as low as $2.5 \%$. The incidence of surgical evacuation in this study may reflect the protocol of the hospital in second trimester abortions.

The induction to delivery interval increased with increasing gestational age in both groups. We also had rates of fetal expulsion of $100 \%$ in both groups at a gestational age between 13-17 weeks which decreased with advancement of gestational age. This is in agreement with other investigators' findings. Gómez et $a{ }^{[11]}$ found that the mean induction-toabortion interval increases by 4 hours after 20 weeks GA. Hamoda et al. ${ }^{[12]}$ in another study on mid-trimester medical termination of pregnancy concluded that the induction to abortion interval was significantly longer in the higher gestational age pregnancies. Similar finding were reported by Dilbaz et al. ${ }^{[13]}$.

We used a misoprostol dose of 400 microgram administered every 4 hours. Doses of 600 and $800 \mu \mathrm{g}$ have shown comparable successful abortion rates but were associated with high rates of side effects.

Wong and colleagues ${ }^{[14]}$ compared the efficacy and side effects of 400 microgram misoprostol administered every 3 and every 6 hours. They concluded that the 
three-hour regime was more effective in terms of a significantly shorter drug administration to abortion interval on the expense of more side effects. We had no significant difference in the incidence of side effects between both groups. Side effects are less common with the vaginal route compared to other routes of administration.

\section{CONCLUSION}

The use of a weighted trans-cervical Foley's catheter filled with $30 \mathrm{ml}$ saline improve the effectiveness of 400 $\mu \mathrm{g}$ vaginal misoprostol in terminating mid trimester pregnancies as reflected by a shorter induction to delivery interval with no significant increase in the incidence of side effects.

\section{CONFLICT OF INTEREST}

There are no conflicts of interests.

\section{REFERENCES}

1. Lalitkumar S, Bygdeman M, Gemzell-Danielsson K (2007): Mid-trimester induced abortion: a review. Hum Reprod Update; 13(1): 37-52.

2. Whitley KA, Trinchere $\mathrm{K}$, Prutsman $\mathrm{W}$, et al. (2011): Midtrimester dilation and evacuation versus prostaglandin induction: a comparison of composite outcomes. Am J Obstet Gynecol; 205:386.e1-7.

3. World Health Organisation(1997):medical methods for termination of pregnancy: report of a WHO scientific groupWHO Technical report series No,871

4. Bryant AG, Grimes DA, Garrett JM, et al. (2011): Second-trimester abortion for fetal anomalies or fetal death: labor induction compared with dilation and evacuation. Obstet Gynecol;117: 788-92.

5. Yapar EG, Senöz S, Urkütür M, et al. (1996): Second trimester pregnancy termination including fetal death: comparison of five different methods. Eur J Obstet Gynecol Reprod Biol.; 69(2): 97-102.
6. Wildschut H, Both MI, Medema S, et al. (2011): Medical methods for mid-trimester termination of pregnancy (Review), The Cochrane Collaboration.

7. Sciscione A, Larkin M, O'Shea A, et al. (2004): Preinduction cervical ripening with the Foley catheter and the risk of subsequent preterm birth. Am J Obstet Gynecol.; 190(3): 751-4.

8. Bani-Irshaid I, Athamneh TZ, Bani-Khaled D, et al. (2006): Termination of second and early third trimester pregnancy: comparison of 3 methods. East Mediterr Health J.; 12(5): 605-9.

9. Onge RD and Conners GT. (1995): Preinduction cervical ripening: a comparison of intracervical prostaglandin E2 gel versus the Foley catheter Am J Obstet Gynecol.; 172(2 Pt 1): 687-90.

10. Ashok PW, Templeton A, Wagaarachchi PT, et al. (2004): Midtrimester medical termination of pregnancy: a review of 1002 consecutive cases Contraception. 69: 51-58.

11. Gómez Ponce de León R, Wing DA. (2009): Misoprostol for termination of pregnancy with intrauterine fetal demise in the second and third trimester of pregnancy - a systematic review. Contraception; 79(4): 259-71.

12. Hamoda H, Ashok PW, Flett GM, et al. (2005): A randomized trial of mifepristone in combination with misoprostol administered sublingually or vaginally for medical abortion at 13-20 weeks gestation. Hum Reprod.; 20(8): 2348-2354.

13. Dilbaz S, Caliskan E, Dilbaz B, et al. (2004): Frequent low-dose misoprostol for termination of second-trimester pregnancy. Eur J Contracept Reprod Health Care; 9(1): 11-5.

14. Wong KS, Ngai CS, Yeo EL, - (2000): A comparison of two regimens of intravaginal misoprostol for termination of second trimester pregnancy: a randomized comparative trial. Hum Reprod.; 15(3): 709-12. 